\title{
Locating Spatial Opportunities for Nature-Based Solutions: A River Landscape Application
}

\author{
Paulina Guerrero ${ }^{1,2, *}$, Dagmar Haase ${ }^{2,3}$ and Christian Albert ${ }^{1}$ (1) \\ 1 Institute of Environmental Planning, Leibniz Universität Hannover, Herrenhäuser Str. 2, 30419 Hannover, \\ Germany; albert@umwelt.uni-hannover.de \\ 2 Department of Geography, Humboldt University of Berlin, Rudower Chausee 16, 10099 Berlin, Germany; \\ dagmar.haase@ufz.de \\ 3 Department of Computational Landscape Ecology, Helmholtz Centre for Environmental Research-UFZ, \\ Permoser Str. 15, 04318 Leipzig, Germany \\ * Correspondence: guerrero@umwelt.uni-hannover.de
}

Received: 30 August 2018; Accepted: 7 December 2018; Published: 17 December 2018

check for updates

\begin{abstract}
Compared to technical infrastructure, nature-based solutions (NBS) strive to work with nature and to move beyond business-as-usual practices. Despite decades of research from various academia fields and a commencing mainstreaming of the term, a lack of cohesiveness and pertinent methods regarding the subject matter hinders further implementation. Using a functional landscape approach, this paper aims to identify the spatial extent of existing and potential NBS locations and applies it across a case study in Germany. Inspired by hydrological models, which work with delineated hydrological response units, this research instead defines hydromorphological landscape units (HLU) based on biophysical spatial criteria to identify the potential areas that could function as NBS. This approach was tested for floodplain-based NBS. The identified HLU were then compared with historical floodplain and land-use data to differentiate between active or potential NBS. The spatial delineation identified 3.6 million hectares of already active floodplains areas, for which we recommend continued or modified protection measures, and 0.4 million ha where the hydromorphological conditions are apt to support floodplains, yet are cut-off from the flooding regime and require rehabilitation measures. The identification of NBS through explicitly defined HLU serves as a spatial approach to support NBS implementation. Taken together, our research can provide an essential contribution to systemize the emerging scholarship on NBS in river landscapes and to help in selecting and planning appropriate NBS in practice.
\end{abstract}

Keywords: river restoration; nature-based solutions; spatial analysis; floodplains

\section{Introduction}

In many regions of Europe, efforts to support transitions of the river landscape towards more sustainable pathways face dramatic land- and water-borne challenges. Established key direct drivers of river degradation are infrastructure development, land conversion, water withdrawal, eutrophication and pollution, overharvesting and overexploitation, and the introduction of invasive alien species [1]. Recommendations emphasize that in order to diminish water-stressors and promote rehabilitation efforts in highly impacted areas, integrative strategies instead of the current fragmentary approaches to management must be replaced [2,3]. Explicitly said, actions for rivers that offer multiple positive benefits for humans and nature must become the mainstream option.

Nature-based solutions, commonly known as NBS, have been coined to encompass the solutions available that provide opportunities for alleviating water-related challenges. NBS are considered to be "interventions which use nature and the natural functions ... to tackle some of the most pressing 
challenges of our time" [4]. "Inspired by, supported by or copied from nature", NBS may be considered an "umbrella term" to help incorporate nature into decision-making [5,6]. Eggermont argues the term is more specifically connected to the concepts of systems agriculture and green infrastructure, and, that in structural practice, it has the most similarities to ecological engineering [7]. These types of solutions aim to alleviate water-related challenges, such as flood, droughts, and water quality deficits in sustainable ways by 'harnessing' ecological processes. The 2018 United Nations World Water Report notably advocated the call for more NBS implementation and provides evidence for the benefits and risk-reduction capabilities of floodplain-based NBS, such as reconnecting and protecting floodplains [8]. Floodplains, for example, can have the capacity to manage infiltration, overland flow, improve hydrological connectivity, regulate water supply, serve as biodiversity hotspots, and provide countless other benefits [8]. However, the degree to which floodplains can fulfill those functions depends on the presence and interaction of various biophysical factors.

In river landscapes, NBS contend with clearly established conventional options, such as dams and weirs, which have standardized implementation processes and short-term returns on investment $[9,10]$. Additionally, technical, hard-engineering solutions are often implemented at reduced spatial and temporal scales, which serve to ease their acceptance [11]. Technical measures have been widely established in river basins throughout the world as flood protection measures, yet, research shows that: (1) These measures alone cannot provide complete protection against floods, and (2) the counter, non-structural measures, such as floodplain extension and creating wetlands, are mostly limited in extent, or non-existent [12]. A key global assessment of the state of the world's freshwaters concluded that water challenges are "broadly coincident with the widespread presence of engineering works that enable the overuse and mismanagement of water" [3]. The inflexible and mono-solution infrastructure of previous decades needs to be properly gauged against multi-functioning NBS.

To advance the uptake of NBS, there is currently a demand for methods which ease implementation of NBS and are useful for practitioners [5,13]. Thus, as a first step towards identifying, planning, and actually implementing NBS in river landscapes, knowledge is needed on how NBS are spatially located, or where proper conditions exist for implementing NBS. There is currently a lack of information, and, consequently, it remains difficult to estimate the extent of where NBS are already used or implemented and where their implementation is required. A localization of NBS that takes advantage of functional unit delineation, as utilized in the fields of landscape planning and hydrological modeling, remains to be tested for NBS to create spatial units that may be planned [14-16]. In many cases, these NBS are composed of biophysical functions that behave according to certain natural laws, such as sediment deposition of river meanders or topographical low points of floodplains.

Thus, taking these considerations into account, this paper focuses on NBS for river landscapes, which include concepts, such as floodplain protection, wetland creation, and the preservation of upstream forests, among others. The aim of this paper is to spatially identify existing and potential locations for NBS using a hydrological landscape units (HLU) approach applied to a river basin in Central Germany. More specifically, the objectives of this research are (i) to present a spatial methodology that supports the initial phases of planning, and (ii) to differentiate between the actual and potential locations of floodplain-based NBS. Our intention to find locations for NBS by using the proxy of the HLU approach is not to estimate the amount of ecosystem functions or services provided in those locations, which would require a much more complex analysis, considering the greater number of relevant biophysical factors. Instead, we want to identify spaces (how many?) and places (where?), which are most likely to fulfil essential ecosystem functions and to serve as NBS. We expect our results to help concretize the current debate around NBS by expanding upon existing conceptual approaches and spatially identifying locations of existing and opportunity spaces for NBS. 


\section{Study Area}

The focus of this study is the Lahn river landscape in Hesse, Germany, Figure 1. The Lahn River was selected as the study site, since it is currently considered as a pilot test case in the EU and Germany for the future transformation of rivers from shipping corridors to natural habitats [17].

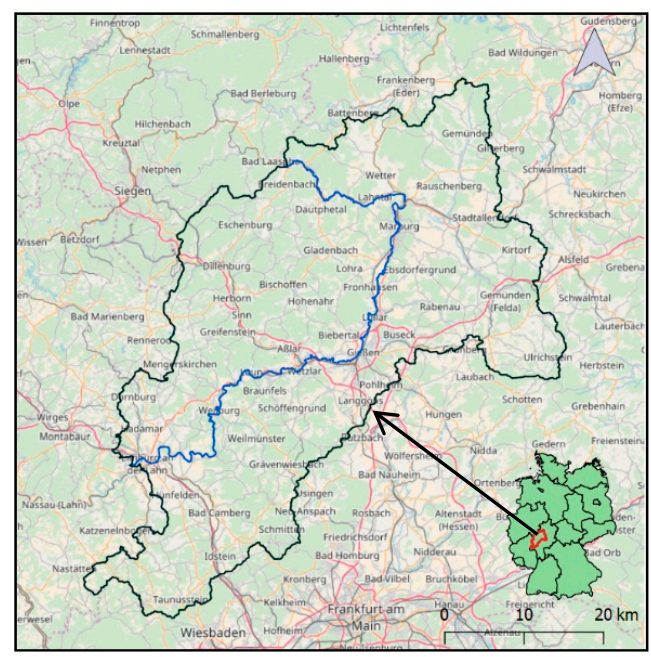

Figure 1. Map of the Lahn River in Germany [18].

As a vital tributary of the river Rhine and with a total catchment area of $5931 \mathrm{~km}^{2}$, the Lahn River runs through three states in Germany, with the majority of its course found in the state of Hesse $\left(4757 \mathrm{~km}^{2}\right)$. The land use of the Lahn watershed consists of $70 \%$ agricultural, $16 \%$ forest, and $14 \%$ urban [19]. The floodplain of the Lahn, which reaches a maximum width of $2.5 \mathrm{~km}$ just downriver from Giessen, is primarily cultivated or used for grazing; hillslopes in the study reach are generally forested [19]. See Figure 2 for a general land use map.

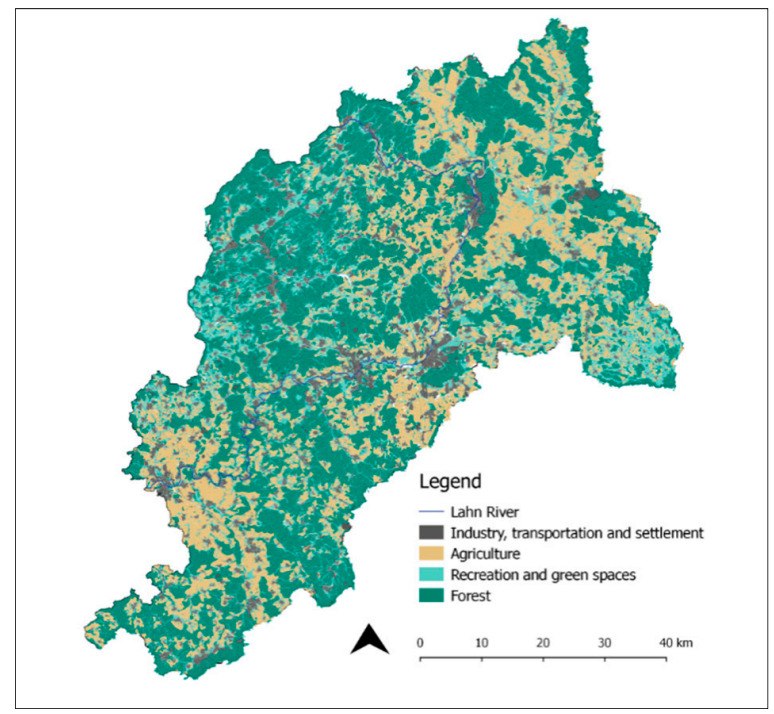

Figure 2. Map of general land uses in the Lahn River in Hesse [20].

According to the profiles of German stream types, the Lahn River is a type 9.2 large highland river exhibiting high habitat diversity, very dynamic flow with high discharge fluctuations, and pronounced discharge events [21]. The majority of the Lahn River's floodplains have a reported status ranging from "significantly modified" up to the "heavily modified" status [17]. This indicates a river whose flow, course, and natural dynamics have been significantly affected. The lower part of the Lahn 
River contains numerous dams and locks that allow for shipping transport. At the same time, this infrastructure also hinders the migrations of fish, such as salmon, and creates difficulties for kayakers and other recreational users [22]. Another additional problem that the Lahn faces is its current water quality, which is currently categorized as a Grade II, or a moderately burdened river, and its ecological status as "unsatisfactory" or "bad," according to the EU's Water Framework Directive reporting [17]. Sources of this pollution can be partially traced back to agricultural and former mining pressures, which diffuse contaminants, including heavy metals, that filtrate down the watershed and floodplain and eventually flow into the river itself $[17,23]$.

Furthermore, once a heavily transited waterway for ship transport, the Lahn has recently experienced a notable decrease in transport volume [17]. Due to this shift, the river currently serves as a potential pilot concept in Germany for dealing with the re-categorization of rivers away from inland waterways towards a new categorization of rivers as ecological and nature protection areas [17,24]. This future transformation of rivers to a more natural river course is spearheaded by the Blue Belt Program of the German government [24]. Additionally, the Living Lahn Program, recipient of a 10-year EU Life grant, has the specific goal to improve the ecological state of the river and ensure it is liveable for all stakeholders [25]. For this reason, this case study provides a window for NBS implementation and serves as a fitting test case for our spatial identification approach.

\section{Method}

The research design of this study consists of a natural-functional reference of units based on biophysically defined spatial criteria for the NBS in question. These units are explored in a mapping exercise for the case study region of Hesse, Germany, in order to identify the extent of a sample NBS and possible, suitable areas of opportunity.

While NBS are indeed often interpreted as an umbrella term capturing many different solutions, particular NBS types and NBS actions are "determined by the natural function of ecosystems." Based on those conditions, science can identify spatial requirements that need to be fulfilled for a particular NBS action to be in place, or to be successfully implemented in the future [26]. Along this line, we suggest that the NBS type, 'working floodplain', requires the protection, enhancement, or restoration and revitalization of river floodplains $[8,25,26]$. Morphological floodplains can be regarded as a good proxy indicator for the opportunity space where the NBS 'working floodplain' currently is or could potentially be located. However, it depends on the degree to which the particular area is still fulfilling the ecological functions of floodplains to determine whether a site presents an area with a working NBS, with potential for future establishment of an NBS, or if the establishment of such an NBS is impossible at this place.

\subsection{Use of the Hydrological Response Unit Method to Develop Spatial Units for NBS}

For our methodology, we utilized the hydrologic response unit, HRU, delineation approach and adapted it to locate floodplain-based NBS in our case study. The HRU concept stems from hydrological models, such as Soil and Water Assessment Tool (SWAT, United States Department of Agriculture, Temple, TX, USA) and Precipitation Runoff Modeling System (PRMS, U.S. Geological Survey, Reston, VA, USA), which work with hydrological response units [27,28]. HRU are homogenous units containing the same soil, land use, and slope characteristics $[15,28]$. These HRU indicate the conditions for water processes and consequently aid in modeling the water balance for watersheds [28,29]. In other words, the HRU delineation method serves to represent similar hydrologic behavior in each land unit.

Inspired by this methodology, we defined biophysical criteria in order to obtain spatial units of homogenous constitution relating to the NBS encompassing floodplains, including the protection and enhancement of these areas. Specifically, we looked to identify areas in the river landscape containing uniform criteria capable of supporting floodplains. We consider these units: Hydromorphological landscape units, or HLU. Thus, HLU are akin to what hydrologist and soil scientist consider HRU. 
The HLU development process to define floodplain-related NBS, and other possible features and NBS, are shown below, see Figure 3.

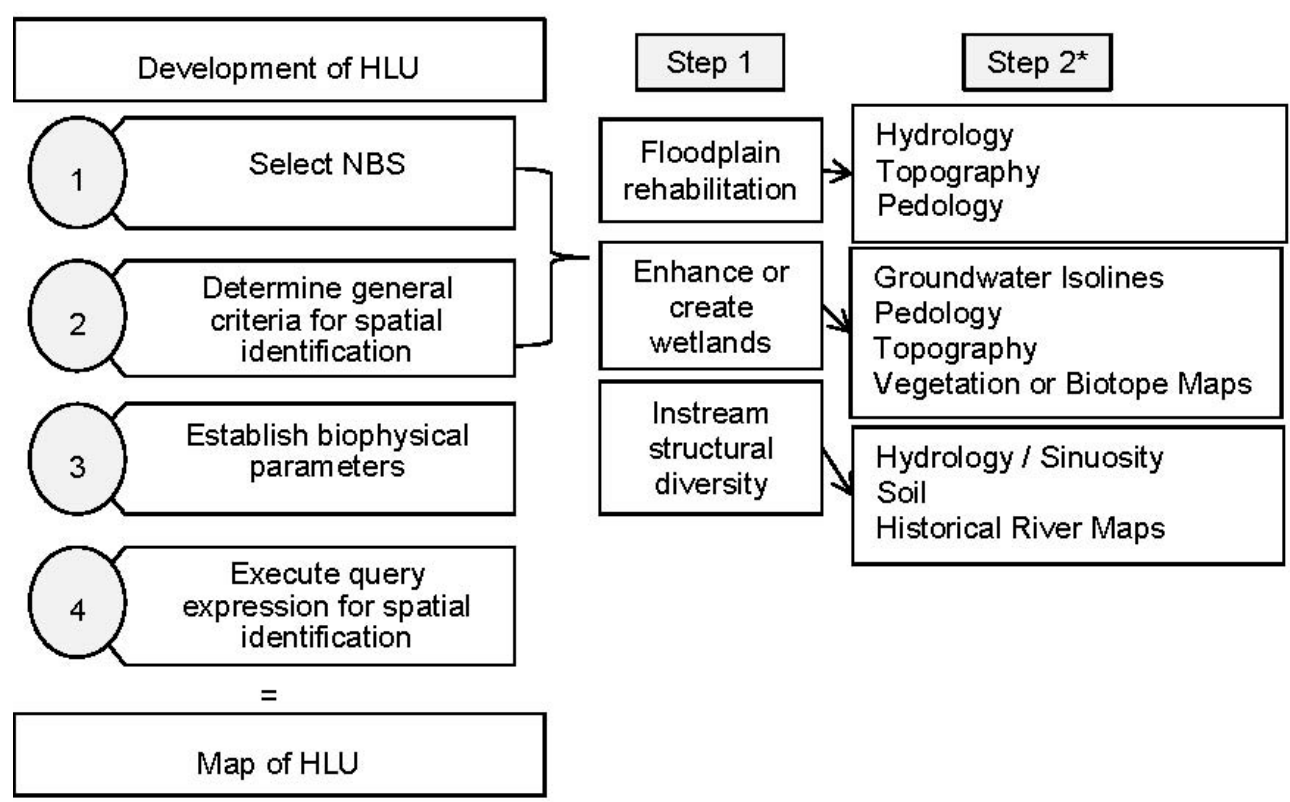

Figure 3. Methodological process for HLU (Hydromorphological landscape units) development.

\subsection{Application of the HLU Approach to the NBS Relating to Floodplains}

Figure 3 shows other possible NBS and the parameters that could be used to develop an HLU. For example, when looking to identify NBS related to wetlands (step 1), such as wetland extension or wetland construction, the criteria for the HLU development (step 2) could include critical wetland identification parameters, such as groundwater isolines, wetland specific pedology, topography, and vegetation native to wetlands. These should be scientifically sound and spatially plausible concepts that may be united to develop an identifying unit. The biophysical parameters should be decided upon based on scientific research and local conditions (step 3), such as the inclusion of specific hydrophilic wetland species. The spatial query (step 4) should single out the established criteria and then combine this data to then provide a visual result of the qualifying locations. These outlined criteria in step 2, while not all tested for this research, have the potential to be incorporated in a spatial analysis, and serve as transparent homogenous units for the corresponding features [30].

To test the HLU methodology, working floodplains and as such floodplain-based NBS, including the revitalization of floodplains, was selected. For the purpose of identifying the initial floodplain HLU, and the active and potential floodplain HLUs, a conceptual model was created through the use of criteria and specific threshold values using GIS (geographical information systems) software [14,31]. See Table 1 input data for data description.

Table 1. Input data and sources $[18,20,32,33]$.

\begin{tabular}{|c|c|c|c|}
\hline Data & File Type & Source & Scale \\
\hline Digital Elevation Model & Raster & WorldClim & $30 \mathrm{~m} \times 30 \mathrm{~m}$ \\
\hline Soil Map & Shape & $\begin{array}{l}\text { Office for Nature, Environment and } \\
\text { Geology of the state of Hesse (HLNUG) }\end{array}$ & $1: 50,000$ \\
\hline Watercourse & Shape & $\begin{array}{l}\text { Federal Agency for Cartography and } \\
\text { Geodesy (BKG) }\end{array}$ & $1: 50,000$ \\
\hline $\begin{array}{l}\text { Land Cover Germany } \\
\qquad(2013)\end{array}$ & Shape & $\begin{array}{l}\text { Federal Agency for Cartography and } \\
\text { Geodesy (BKG) }\end{array}$ & $1: 50,000$ \\
\hline Floodplain State & Shape & $\begin{array}{c}\text { German Federal Institute of } \\
\text { Hydrology (BfG) }\end{array}$ & $1: 50,000$ \\
\hline
\end{tabular}


The criteria and parameters to spatially identify the extent of the floodplain HLU were defined. Just as with rivers, distinct classifications exist for floodplain identification [30]. In the various definitions for floodplains, there exists a variety of criteria considered for characterizing floodplains, ranging from suspended sediments, organisms present, soil types, topography, seasonal inundation, adjacency to river, and many others [30,34]. In this study, we focused the criteria on the natural, geomorphological aspects for the identification of floodplains. Areas defined by flood risk assessments, known as floodways, flood flows, or flood hazard areas, were not used for the spatial identification of a floodplain. Defining the floodplain extent via the inundated area during floods of a particular return period poses complications, since the flooding frequency could be a restricting factor [34]. Therefore, we did not consider inundated areas or flood risk areas in our HLU criteria, as in this study, we set out to define natural, biophysically focused criteria apt to support a floodplain and floodplain-related NBS, rather than statistically based inferences.

The criteria selected looked to be inclusive of key floodplain factors and definitions. Additionally, it considers floodplain formation processes and, critical to this study, requirements that can be spatially related $[30,31]$. Thus, we considered flat valley areas, presence of specific sediments, and hydrological requisites as criteria for spatially identifying floodplains $[2,14,30,31,34]$. The following three criteria were selected:

- $\quad$ Sediments;

- $\quad$ topography; and

- hydrology.

The floodplain HLU is defined as:

$$
\text { F_HLU }=f(\mathrm{~S}, \mathrm{~T}, \mathrm{H})
$$

where $\mathrm{S}$ is sediments, $\mathrm{T}$ is the topography, and $\mathrm{H}$ is the hydrological criteria. More precisely, the HLU itself is composed of the areas conforming to the previous criteria, which adhere to the specific parameters of Equation (2):

$$
\mathrm{F} \_ \text {HLU }=\mathrm{S}_{\mathrm{o}, \mathrm{a}}+\mathrm{T}_{\leq 3^{\circ}}+\mathrm{H}_{\leq 5} \mathrm{~km}
$$

where $S_{0, a}$ are organic and alluvial sediments, $T_{\leq 3^{\circ}}$ are areas with a slope less than or equal to $3 \%$, and $\mathrm{H}_{\leq 5} \mathrm{~km}$ limits a distance of no more than $5 \mathrm{~km}$ from the river. See Table 2.

Table 2. Criteria and parameters for floodplain HLU.

\begin{tabular}{cc}
\hline Criteria & Parameter for Inclusion \\
\hline Pedology (sediments) & Organic and alluvial sediments \\
Topography & Relief energy (slope) $\leq 0.03$ \\
Hydrology & Distance to river $\leq 5 \mathrm{~km}$ \\
\hline
\end{tabular}

Both organic and alluvial sediments were selected for the sediment parameters as these are key indicators of stream presence; these are sediments that have been shaped and deposited by river processes in some form [14,30,34]. A relief of $3 \%$ was the selected relief threshold as it represents the average maximum relief of floodplains considering distinct stream classifications, including the Montgomery and Buffington Stream Classification and the Rosgen Stream Types [14,30]. The $5 \mathrm{~km}$ buffer includes those areas adjacent to the river and is inclusive of bankfull depth criteria, floodplain valley morphology, and goes beyond the flood risk area of HQ 200, or 200-year flood estimations; this last criterion is incorporated in order to be inclusive of a wider flooding potential area, rather than restrictive [30]. While the $5 \mathrm{~km}$ delineation is considered suitable in this setting due to the criteria set out above, it may not be applicable for all rivers as the specific characteristics of the river, such as the type, valley morphology, and other hydrological and morphological aspects, also need to be taken into account. 
With the criteria and parameters for the HLU determined, we ran queries, specifying the parameters for the corresponding thematic spatial layers. This part of the analysis was done on the geographical information systems, QGIS and ArcGIS [35,36]. The resulting layers where then processed, intersected, and joined. These resulting HLU are those areas with the combined biophysical characteristics, which have the capacity to support a floodplain presence in terms of sediments, topography, and hydrology. These units can also be considered the general spatial extent for floodplains and are consequently used for the floodplain-based NBS distinction.

\subsection{Distinction Between Potential and Active HLU}

A further spatial analysis was carried out in order to differentiate between the potential and active floodplain HLU. Active floodplains were defined as those areas under a permeable land use and located in the recent floodplain; see Table S1 in the Supplementary Material for land use permeability classification:

$$
\mathrm{F}_{-} \mathrm{HLU}_{\mathrm{A}}=\mathrm{F} \_\mathrm{HLU}-\left(\mathrm{LU}_{\mathrm{p}}+\mathrm{FP}_{\mathrm{r}}\right)
$$

where $\mathrm{LU}_{\mathrm{p}}$ are permeable land use areas and $\mathrm{FP}_{\mathrm{r}}$ are the recent, or current, floodplains areas.

Potential floodplain areas are those HLU which are presently located under a sealed land use and found in the historical floodplain stretch:

$$
\text { F_HLUP }=\text { F_HLU }-\left(\mathrm{LU}_{\mathrm{s}}+\mathrm{FP}_{\mathrm{h}}\right)
$$

where $\mathrm{LU}_{\mathrm{s}}$ are the sealed land use areas and $\mathrm{FP}_{\mathrm{h}}$ are the historical floodplains areas.

As per the data used, a recent floodplain is defined as areas that can currently be flooded, while the historical floodplain is defined as the area that is cut off from the natural flooding regime due to infrastructure, such as levees, and is no longer able to flood, i.e., a non-functioning remnant of the floodplain [37]. Figure 4 displays a scheme of data and model integration for the HLU floodplains; this expands steps 1-4 of Figure 3.

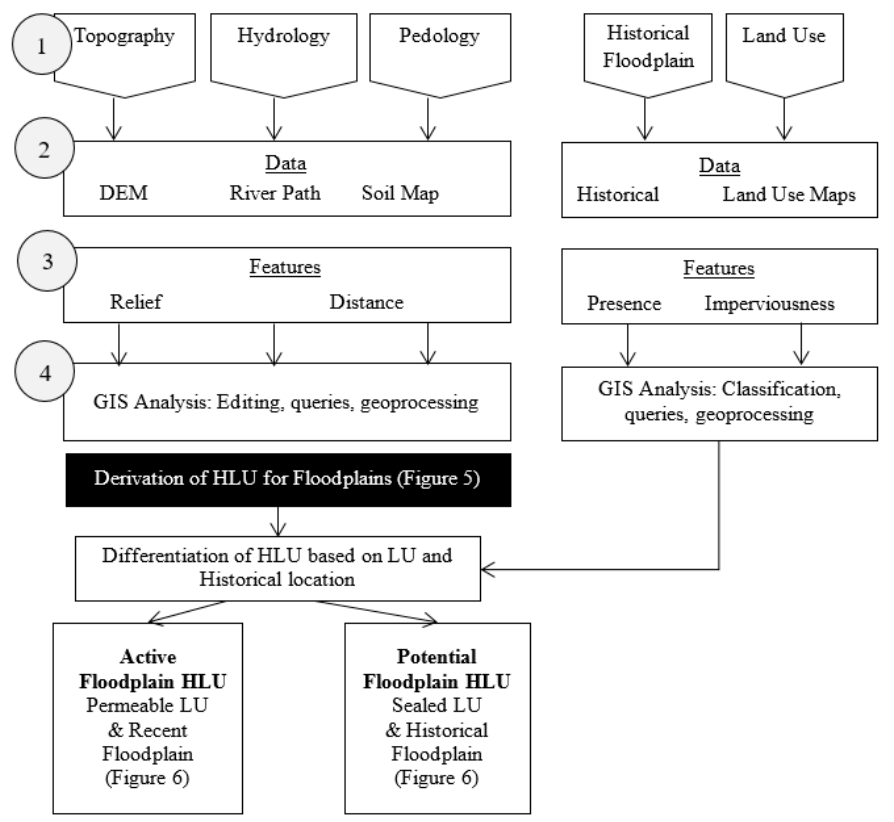

Figure 4. Scheme of data and model integration for the HLU assessment regarding floodplainbased NBS.

The visualized distinction between the permeable and sealed land use employed, as well as the above-described differentiation of recent and historical delineation of floodplains can be found in the Figure S1 in Supplementary Materials. 


\section{Results}

Modelling the Extent of Floodplains through HLUs

Utilizing the concept of hydromorphological land units, we found that the Lahn River in Hesse is comprised of 6565.30 ha, which can be considered as floodplain HLU. These HLU are found throughout the analysed study area, as seen in Figure 5, with a distinct concentration of HLU in the upper reaches of the area in question. The combination of the sediment, topography, and hydrology parameters allows for a clear identification and visualization of these natural functional units.

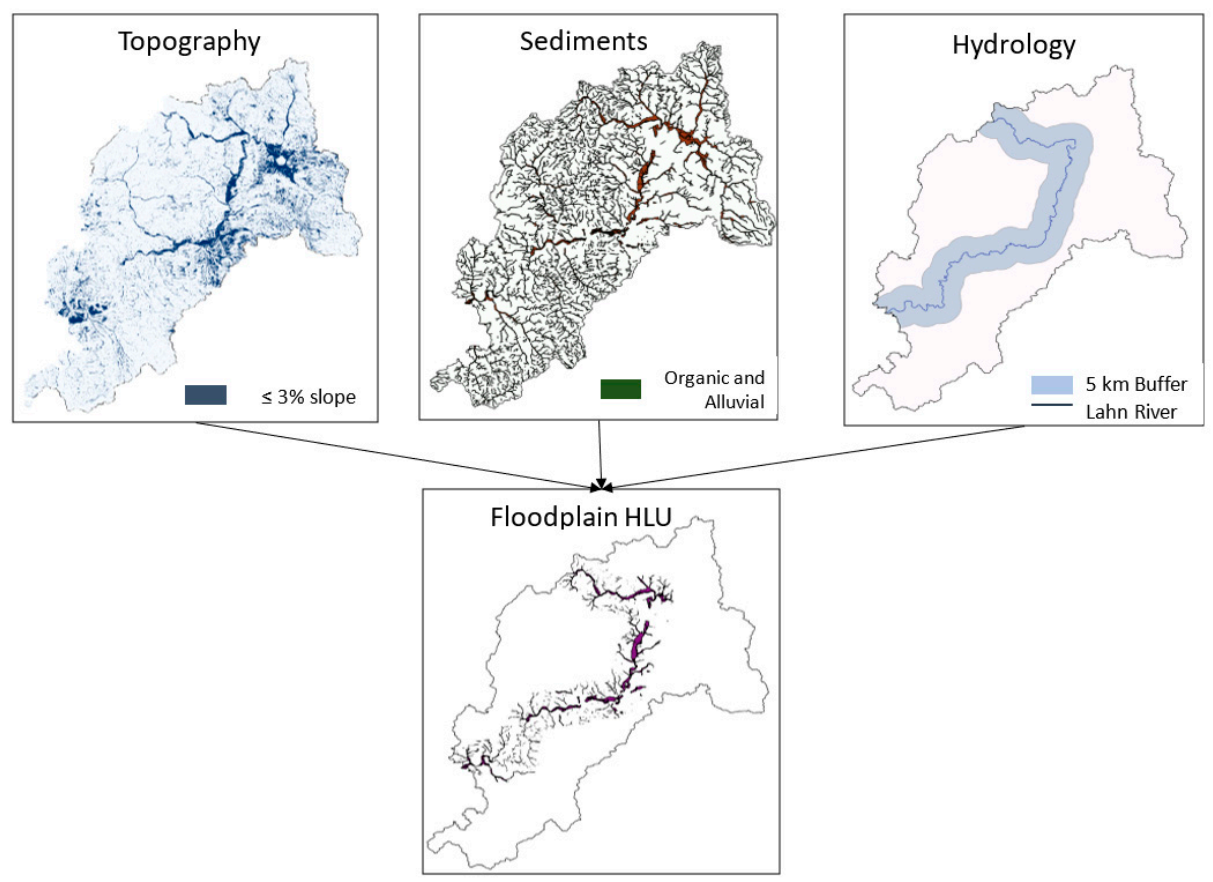

Figure 5. Visualized parameters and the resulting spatial extent of the hydromorphological land units, HLU, for floodplains in Hesse. Further results show a marked distinction between the active floodplain HLU extent, i.e., those HLU currently under permeable land use and located in the recent area of the floodplain, versus the potential floodplain HLU, i.e., areas located under a sealed land use and in the historical floodplain, see Figure 6 and Table 3.

\section{Floodplain HLU}
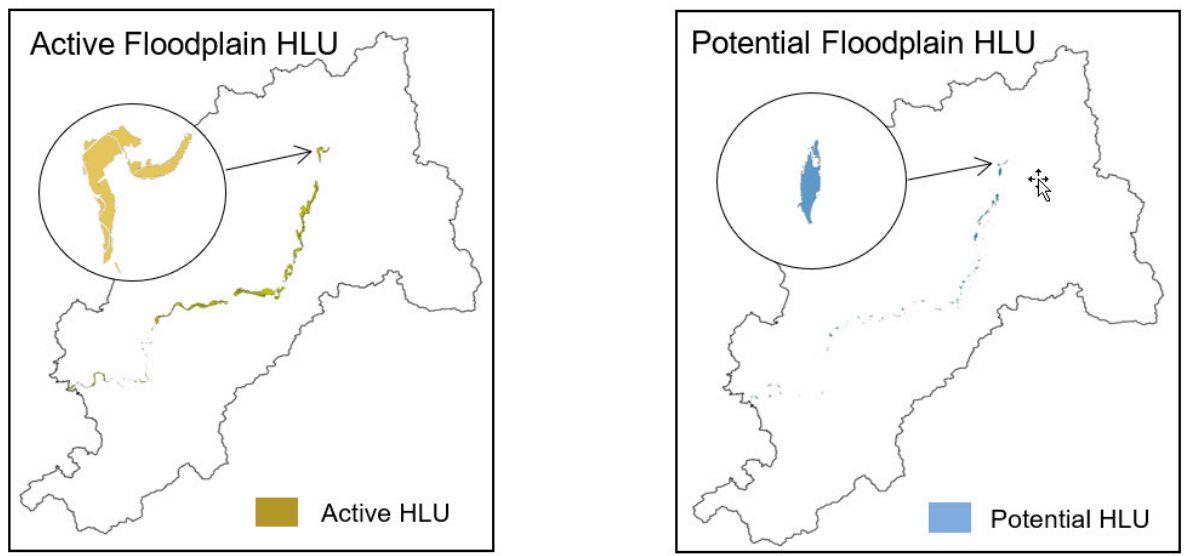

Figure 6. Differentiation between active and potential floodplain HLU in Hesse. 
Table 3. Area extent and size distinctions of the active and potential floodplain HLU.

\begin{tabular}{ccc}
\hline & Active Floodplains & Potential Floodplains \\
\hline Total Area (ha) & 3082.78 & 343.89 \\
Largest (Max) Area (ha) & 364.79 & 39.81 \\
Average Area (ha) & 2.94 & 0.93 \\
No. of Areas $\geq 50$ ha & 18 & 0 \\
No. of Areas $\geq 20$ ha & 40 & 4 \\
No. of Areas $\geq 10$ ha & 51 & 6 \\
No. of Areas $\geq 5$ ha & 69 & 17 \\
\hline
\end{tabular}

In this particular case, the active floodplain HLU have a total area presence of approximately $3083 \mathrm{ha}$, while the potential areas have a noticeably smaller extent of $344 \mathrm{ha}$. This is close to nine times more in total area cover by the active floodplain units than the potential units. The active and potential HLU themselves also distinctly vary in their individual size and location. The largest active floodplain HLU has an area of more than nine times the largest potential floodplain HLU, with corresponding sizes of 365 ha and 40 ha. The area illustrated in Figure 6 is smaller than those displayed in Figure 5 since the latter figure considered two additional selection criteria, namely land use (i.e., permeability) and historical extent. These criteria, especially the historical floodplains, cover a more restricted land area in the river's surroundings, leading to an area of a smaller size.

Both the active and potential HLU identified are present throughout the Lahn River in Hesse. Yet, there is a notable decrease in the presence of both unit types in the lower part of the river stretch, with few HLU to be seen. This is an area of river terraces, or elevated areas adjacent to a river where the topographical conditions limit a connected floodplain presence [34]. While the actual HLU dominate in presence at all parts of the river course, the potential HLU are mostly found in the upper region of the Lahn River.

Figure 7 presents a more focused area extent of the Lahn River where the distinction between the actual, i.e., today's active floodplains, and potential HLU for floodplain-related NBS, such as revitalisation, locations are clearly visualized. The yellow areas represent the actual HLU identified as a floodplain and, as of present day, allowed to function as such. In this case, these yellow areas are under agricultural land use and water can filtrate into the ground. In comparison, the blue areas depict the areas identified to have a potential to hold a floodplain-based NBS, yet are currently restricted from functioning as floodplains. In this case, both of the blue areas are located under industrial uses and both are found in the historical floodplain demarcation.

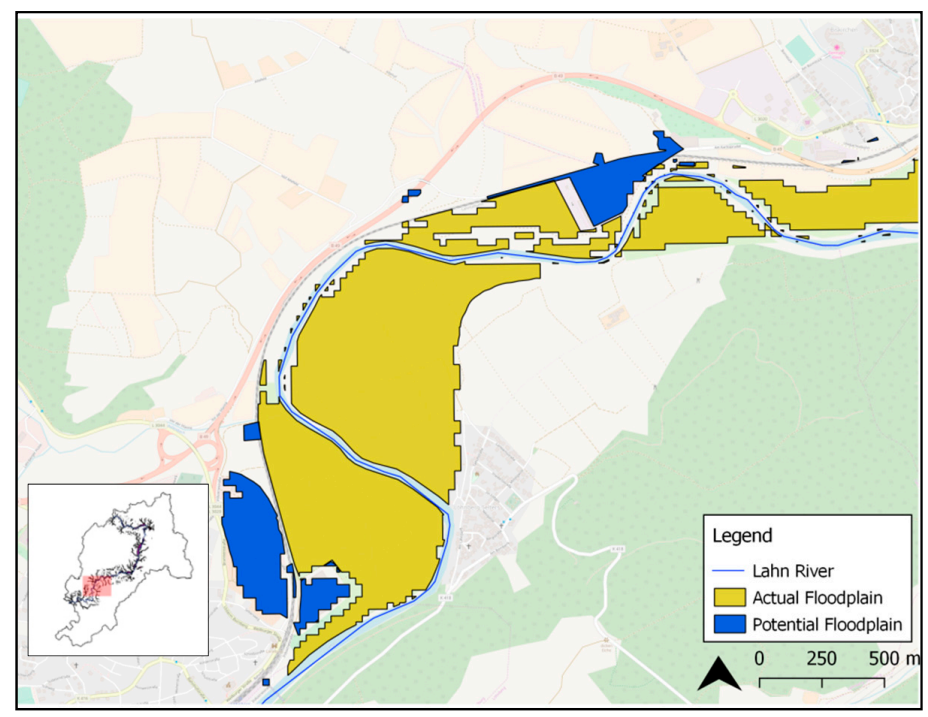

Figure 7. Detailed area with both actual and potential floodplain HLU identified [18]. 
In order to gain a better insight into the location of the identified actual and potential floodplain HLU identified, their extent was compared to flood risk maps, see Figure 8. Results show that the location of actual HLU are mostly located in the areas modelled as having a high probability for flooding events, $\mathrm{HQ}_{10}$ and $\mathrm{HQ}_{20}$, i.e., a 10- to 20-year flood event. This coincides with the concept presented in this research of an actual floodplain HLU, as these are areas with the biophysical characteristics of a floodplain and currently able to serve as such.

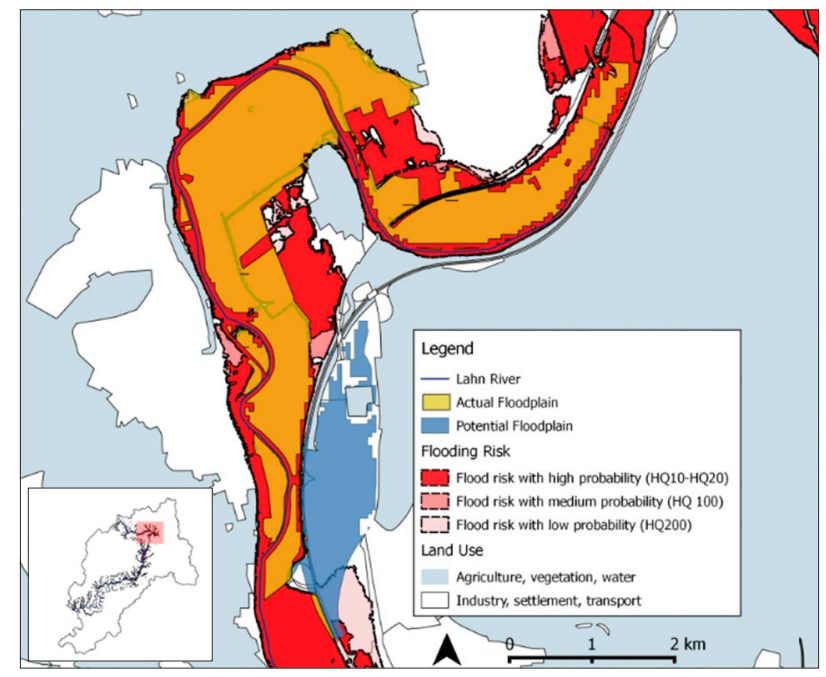

Figure 8. Potential and actual HLU locations in comparison to flood risk areas. Source for flood risk data: [33].

Interestingly, the comparison of the potential areas for floodplain-based NBS, or a potential HLU, shows a highly varied alignment with the flood risk areas. While at some very few instances the potential HLU coincide with the $\mathrm{HQ}_{10-20}, \mathrm{HQ}_{100}$, or $\mathrm{HQ}_{200}$, the majority of the potential HLU areas are not found within these flood risk areas in the Lahn River. These are areas that even in a low probability flood $\mathrm{HQ}_{200}$, i.e., a 200-year flood, which is known for its extensive flooding risk, will not be flooded. This highlights precisely the fact that these potential floodplain revitalization areas are obstructed from the natural flooding process. This coincides with the presence of built-infrastructure, e.g., weirs, highways, and sealed urban zones. It is key to note that engineering techniques for flood control look to prevent exactly this-an overtopping of the channel banks and spillage onto the surroundings [34]. The infrastructure restricts the natural biophysical floodplain from functioning. Thus, even though the topography, sediments, and distance to the river characteristics are present, in reality, these "potential" areas are hindered from actually functioning to their full capacity.

Using the identified floodplain HLU as a background (in yellow), plausible locations of other NBS, such as wetland enhancement and both riparian and forest protection zones, were overlaid, see Figure 9. Here, an explorative configuration of distinct and possible NBS in a river setting can be observed. There is a clear spatial interaction among the various multi-functioning NBS, where both synergies and trade-offs can be detected when one is implemented or modified. For example, when the transformation, or removal, of grey infrastructure, i.e., weirs, is enacted, one of the many consequences that may occur may be that this leads directly to the enhancement of riparian flora and fauna downstream. As the flood-prone areas indicatively show, a more natural water flow will ensue and this could lead to an improved habitat for many species. Here, we see a synergy of the NBS, removal of grey infrastructure, and the consequent enhancement of riparian zones. In contrast, the implementation of constructed wetlands to the north, another NBS, may result in a trade-off with other land uses, such as intensive agriculture, even though the wetlands would serve as a zone to moderate flooding risks, and even better if combined with forest protection areas. However, a trade-off 
would ensue, since instead of allowing for perpetual crop production on this area, constructing a wetland would most likely not permit a continuation of intense agricultural practices.

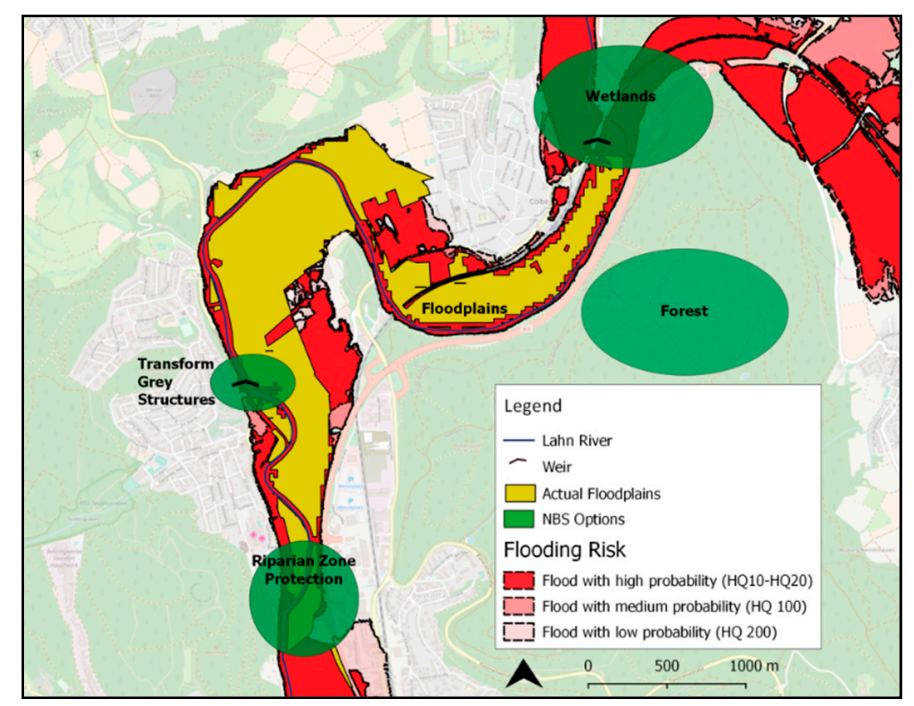

Figure 9. Overlay map exemplifying possible locations for a variety of NBS in an actual area of the Lahn River where spatial synergies and trade-offs are visualized.

\section{Discussion}

This paper presents a spatial delineation of the potential locations for floodplain-based NBS in the Lahn River landscape. A method to link NBS to their biophysical functional units is demonstrated, and the results provide a further understanding of the actual and potential spatial dimensions of NBS. Through the use of hydromorphological land units, or HLU, we identify areas with the biophysical characteristics to "carry" the natural features and related NBS, and these visualizations provide a first glimpse in determining which areas should be protected and which areas can be environmentally improved. Based on an established hydrological method, i.e., HRU, this method can make realistic estimations based on a simple, practical approach that uses public data [15]. Both the pertinence of this method and publicly available data allows not just for an ease in repeatability, but, furthermore, if combined with local data, it has the possibility for transferability to other river case studies.

Additionally, by translating the concept of NBS to a spatial visualization, this research becomes understandable for planners and stakeholders of various disciplines, which can ease communication and decision-making in the landscape planning process. While the final decision, in order to attain a successful restoration, should be dependent upon the case in hand and local knowledge of hydrology and ecology, this output serves as a sounding board for initial planning and decision-making, easing pressure upon the stakeholder and providing a first basis for discussion [38].

Both the use of HRU and landscape units are established methodologies in landscape ecology and hydrology. We combine these approaches to develop units applicable to spatially identify NBS, which is a new planning approach on how to make use of nature to face environmental challenges one can argue. While this combination and the very purpose of creating HLU is novel, we rely on previous research that has focused on identifying natural features and functions through the use of suitable spatial indicators and homogenous units $[14,16,29,31,39]$. The specific parameters for the criteria are based on distinct classifications and methods, which we have compared in Table S2 of the supplementary. The advantages and disadvantages of each criterion are addressed.

The criteria and parameters used for the definition of the HLU, while suitable for this research, are based on literature and pertain to solely hydromorphological processes [14,30,34]. As such, if a finer scale is used or if it is used for a specific application in practice, the criteria needs to be defined accordingly with the relevant data. This is a critical point for any river intervention, as a failure to 
consider local conditions may cause negative, rather than positive, effects $[38,40,41]$. While this method aims to be flexible to include the best available and at best open-source data, the results will benefit from a much finer scale, as coarse input data may not detect fine-resolution processes [42]. A finer spatial scale, especially considering that rivers may often be small or harder to identify, provides more information to understand dynamics and observations that may otherwise be overlooked [42,43].

Additionally, the focus of this study was environmental factors; thus, no assessments relating to social, including stakeholders or economic aspects, took place. While these concepts are critical for the enactment of NBS, this method is meant to be a part of the total evaluation required for NBS planning $[7,11,13,44]$.

In this case study, results show that, in extent and size, the active floodplain areas considerably overshadow those areas with a potential to sustain floodplains. Thus, one may hypothesise that this is a healthy river with many active floodplains. However, a critical aspect to consider is that the distinction of land use between permeable and non-permeable areas plays a key role. The land use distinction considers agricultural land as permeable land, as is so, and many of the active floodplain HLU are consequently located within this land use domain. This land use consideration does not affirm that the state of the river is 'healthy' [22,45]. As previously mentioned, solely biophysical, rather than chemical criteria, encompasses this research. This later aspect should be further included in the proper assessments, since many of these intensive agricultural areas are known to be influencing the water quality of the Lahn through their extensive use of pesticides and nutrients [45]. As for the potential areas located under industrial land uses, the results do not denote that these industrial sites should be eliminated, yet a discussion should at least take place, with the aim to rehabilitate or improve the natural functions of these areas.

The results also note the presence of built infrastructure as impeding floodplain functioning. A clear example of built-infrastructure hindering the natural floodplain process and thus, augmenting the damage in the event of floods by reducing natural retention areas is that of the Elbe river in Germany. The floods of 2002 and 2013 caused vast damage in the region. These events prompted the International Commission for the Protection of the Elbe River, or ICPER, to rethink its flood protection strategy; the commission specifically noted in its Action Plan that the "removal of floodplain" in the past was a mistake $[46,47]$. The actions taken henceforth in the Elbe include, among others, the restoration of former floodplain areas via dyke removal, and thus, allowing the presence of a full-functioning, unrestricted, and active floodplain [47]. Thus, if floodplain-based NBS are considered in river management, then areas facing current flooding risks would likely be reduced as the water would instead have room to flow through, filtrate, and perhaps flood these biophysically adequate attenuation zones.

While in this paper the methodology is not tested in other rivers or for other mentioned NBS, such as wetland enhancement, the fundamental and general scope of the criteria and methodology, i.e., homogenous units based on key biophysical criteria, is feasible and realistic for application. The criteria, as mentioned, was selected based on vast research specifying the three key characteristics of the natural feature, and these characteristics and methodology due to their fulfilment of spatial and scientific qualities have the potential to be applied to other river systems.

The aim of the spatial analysis was to identify NBS locations. Therefore, this did not include further analysis focused on the feasibility of each HLU, nor was the flooding capacity of these areas under examination. The floodplains' performance, in respect to flooding effectiveness, is not assessed. While the flooding effectiveness and flooding risk of these HLU is outside the scope of this research, future research is recommended to expand upon this concept.

\section{Conclusions}

This study adapted the HRU delineation method of water models unto HLU to spatially identify the extent of active and potential locations for floodplain-based NBS and shows promising results for support of decision-making, both in the case study area [48]) and landscape planning in general. 
Additionally, this research serves to provide tangibility to the term, NBS, by defining specific spatially-linked hydromorphological characteristics to an NBS. This transferable and straightforward method can be used by planners and decision-makers as a starting point for NBS discussion and selection. Various groundwater and watershed water balance models and soil erosion models use the HRU concept; our HLU approach is, therefore, complementary and applicable in planning. We combined the use of landscape units with the hydrological unit approach and integrated biophysical characteristics, making this method a triangulation of concepts which follow scientific laws.

We recommend further research that includes social and economic criteria in order to more comprehensively asses the NBS and provide a more robust evidence-base and support NBS implementation in practice.

Supplementary Materials: The following are available online at http://www.mdpi.com/2073-4441/10/12/ 1869/s1, Table S1: Land Use permeability distinction, Table S2: Comparison of HLU criteria with other referenced classifications and methods [14,30,34], Figure S1: Differentiation of land use and historical floodplain status visualized.

Author Contributions: Conceptualization, P.G., D.H. and C.A.; Methodology, P.G. and D.H.; Software, P.G.; Validation, D.H.; Formal Analysis, P.G.; Investigation, P.G.; Resources, P.G. and C.A.; Data Curation, P.G.; Writing-Original Draft Preparation, P.G.; Writing-Review \& Editing, P.G., D.H. and C.A.; Visualization, P.G.; Supervision, D.H. and C.A.; Funding Acquisition, C.A.

Funding: The authors are grateful for the funding support from the German Federal Ministry of Education and Research (BMBF) through the Junior Research Group PlanSmart (funding code: 01UU1601A), the BiodivERsA project ENABLE (COFUND 2015-16), and the Horizon 2020 innovation action CONNECTING (COproductioN with NaturE for City Transitioning, Innovation and Governance; No 730222-2) for fruitful discussions and comments about NBS in wetlands. The publication of this article was funded by the Open Access Fund of the Leibniz Universität Hannover.

Acknowledgments: We would like to thank the four anonymous reviewers for their critical review and insightful suggestions which helped to improve the quality of the manuscript.

Conflicts of Interest: The authors declare no conflict of interest.

\section{References}

1. Millennium Ecosystem Assessment (MEA). Ecosystems and Human Well-Being: Current State and Trends; Island Press: Washington, DC, USA, 2005.

2. Tockner, K.; Bunn, S.E.; Gordon, C.; Naiman, R.J.; Quinn, G.P.; Stanford, J.A. Flood Plains: Critically Threatened Ecosystems. Aquat. Ecosyst. 2005, 45-62. [CrossRef]

3. Vörösmarty, C.J.; McIntyre, P.B.; Gessner, M.O.; Dudgeon, D.; Prusevich, A.; Green, P.; Glidden, S.; Bunnro, S.E.; Sullivan, C.A.; Liermann, C.R.; et al. Global Threats to Human Water Security and River Biodiversity. Nature 2010, 467, 555-561. [CrossRef] [PubMed]

4. International Union for Conservation of Nature (IUCN). Nature-Based Solutions. 2016. Available online: http:/ / www.iucn.org/regions/europe/our-work/nature-based-solutions (accessed on 18 September 2016).

5. Towards An EU Research and Innovation Policy Agenda for Nature-Based Solutions \& Re-Naturing Cities; European Commission: Luxembourg City, Luxembourg, 2015. [CrossRef]

6. Potschin, M.; Kretsch, C.; Haines-Young, R.; Furman, E.; Berry, P.; Baró, F. Nature-Based-Solutions. 2015. Available online: http:/ / www.openness-project.eu/library/reference-book (accessed on 22 October 2016).

7. Eggermont, H.; Balian, E.; Azevedo, J.M.N.; Beumer, V.; Brodin, T.; Claudet, J.; Fady, B. Nature-Based Solutions: New Influence for Environmental Management and Research in Europe. GAIA Ecol. Perspect. Sci. Soc. 2015, 24, 243-248. [CrossRef]

8. World Water Assessment Programme (WWAP). The United Nations World Water Development Report 2018: Nature-Based Solutions for Water; WWAP: Paris, France, 2018.

9. Aylward, B.; Bandyopadhyay, J.; Belausteguigotia, J.-C.; Börkey, P.; Cassar, A.; Meadors, L.; Saade, L. Freshwater ecosystem services. In Millenium Ecosystem Assessment: Ecosystems and Human Well-Being: Current State and Trends; Island Press: Washington, DC, USA, 2005.

10. Travers, A.; Elrick, C.; Kay, R.; Vestergaard, O. Ecosystem-Based Adaptation Guidance; UN Environment Programme, Division of Environment Policy Implementation: Nairobi, Kenya, 2012. 
11. Maes, J.; Jacobs, S. Nature-Based Solutions for Europe's Sustainable Development. Conserv. Lett. 2015. [CrossRef]

12. Krysanova, V.; Buiteveld, H.; Haase, D.; Hattermann, F.F.; van Niekerk, K. Practices and Lessons Learned in Coping with Climatic Hazards at the River-Basin Scale: Floods and Droughts. Ecol. Soc. 2008, 13, 32. [CrossRef]

13. Kabisch, N.; Frantzeskaki, N.; Pauleit, S.; Naumann, S.; Davis, M.; Artmann, M.; Haase, D. Nature-Based Solutions to Climate Change Mitigation and Adaptation in Urban Areas-Perspectives on Indicators, Knowledge Gaps, Barriers and Opportunities for Action. Ecol. Soc. 2016, 21. [CrossRef]

14. Haase, D.; Gläser, J. Determinants of Floodplain Forest Development Illustrated by the Example of the Floodplain Forest in the District of Leipzig. For. Ecol. Manag. 2009, 258. [CrossRef]

15. Kalcic, M.; Chaubey, I.; Frankenberger, J. Defining Soil and Water Assessment Tool (SWAT) Hydrologic Response Units (HRUs) by Field Boundaries. Int. J. Agric. Biol. Eng. 2015, 8, 69-80. [CrossRef]

16. Syrbe, R.U.; Walz, U. Spatial Indicators for the Assessment of Ecosystem Services: Providing, Benefiting and Connecting Areas and Landscape Metrics. Ecol. Indic. 2012, 21, 80-88. [CrossRef]

17. EU LIFE. LIFE Integrated Projects. 2014. Available online: www.lila-livinglahn.de/.../files/.../LIFE_I_ Summary_Website.pdf (accessed on 12 August 2016).

18. OpenStreetMap. 2018. Available online: https://www.openstreetmap.org/copyright (accessed on 11 February 2018).

19. Martin, C.W. Heavy Metal Storage in near Channel Sediments of the Lahn River, Germany. Geomorphology 2004, 61, 275-285. [CrossRef]

20. Bundesamt Für Kartographie Und Geodäsie (BKG). 2017. Available online: https://www.bkg.bund.de/EN/ Home/home.html (accessed on 14 March 2017).

21. Pottgiesser, T.; Sommerhäuser, M. Profiles of German Stream Types. Available online: http://reform. gisinternet.nl/images/2/2b/Pottgiesser_Sommerhaueser_2004.pdf (accessed on 13 December 2018).

22. Von Keitz, S. Living River Lahn. EU Europa, 2015. Available online: http:/ / ec.europa.eu/environment/life/ project/Projects /index.cfm?fuseaction=search.dspPage\&n_proj_id=5438 (accessed on 21 August 2016).

23. Hahn, J.; Opp, C.; Zitzer, N.; Laufenberg, G. Impacts of River Impoundment on Dissolved Heavy Metals in Floodplain Soils of the Lahn River (Germany). Environ. Earth Sci. 2016, 75, 1141. [CrossRef]

24. Bundesministerium für Verkehr und digitale Infrastruktur (BMVI). Bundesprogramm Blaues Band Deutschland. 2017. Available online: http://www.blaues-band.bund.de/Projektseiten/Blaues_Band/ DE/00_Home/home_node.html (accessed on 24 August 2016).

25. European Commission. In-Depth Report: E-Consultation on Nature-Based Solutions; European Commission: Brussels, Belgium, 2014.

26. Thorslund, J.; Jarsjö, J.; Jaramillo, F.; Jawitz, J.W.; Manzoni, S.; Basu, N.B.; Chalov, S.R. Wetlands as Large-Scale Nature-Based Solutions: Status and Challenges for Research, Engineering and Management. Ecol. Eng. 2017, 9. [CrossRef]

27. Markstrom, J.; Regan, S.; Hay, L.; Viger, R.; Webb, R.; Payn, R.; LaFontaine, J. PRMS-IV, the Precipitation-Runoff Modeling System; U.S. Geological Survey: Reston, VA, USA, 2015.

28. University of Texas A\&M. SWAT Input/Ouput File Documentation. 2012. Available online: http:/ / swat. tamu.edu/documentation/2012-io/ (accessed on 22 February 2017).

29. Schmalz, B.; Kruse, M.; Kiesel, J.; Müller, F.; Fohrer, N. Water-Related Ecosystem Services in Western Siberian Lowland Basins-Analysing and Mapping Spatial and Seasonal Effects on Regulating Services Based on Ecohydrological Modelling Results. Ecol. Indic. 2015, 71, 55-65. [CrossRef]

30. Ward, A.D.; Trimble, S.W.; Burckhard, S.R.; Lyon, J.G. Environmental Hydrology; CRC Press: Boca Raton, FL, USA, 2016.

31. Haase, D. Holocene Floodplains and Their Distribution in Urban Areas-Functionality Indicators for Their Retention Potentials. Landsc. Urban Plan. 2003, 66, 5-18. [CrossRef]

32. Fick, S.E.; Hijimans, R.J. Worldclim 2: New 1-Km Spatial Resolution Climate Surfaces for Global Land Areas. 2017. Available online: http:/ / worldclim.org/version2 (accessed on 2 October 2017).

33. Hessisches Landesamt Für Naturschutz, Umwelt Und Geologie (HLNUG). 2018. Available online: https:/ / www.hlnug.de/themen/geografische-informationssysteme/geodienste/wasser.html (accessed on 17 January 2018).

34. Goudie, A.S. Encyclopedia of Geomorphology, 1st ed.; Routledge: Abingdon, UK, 2014. 
35. Environmental Systems Research Institute (ESRI). ArcGIS; ESRI: Redlands, CA, USA, 2018.

36. QGIS Development Team. QGIS Geographic Information System; Open Source Geospatial Foundation Project: Las Palmas, Spain, 2018.

37. Dister, E.; Fünther-Diringer, D. GIS-Gestützte Bewertung von Flüssen Und Strömen in Mitteleuropa Untersuchte Flüsse; Bundesamt für Naturschutz: Bonn, Germany, 2004.

38. Palmer, M.A.; Bernhardt, E.S. Hydroecology and River Restoration: Ripe for Research and Synthesis. Water Resour. Res. 2006, 42, 2-5. [CrossRef]

39. Babbar-Sebens, M.; Barr, R.C.; Tedesco, L.P.; Anderson, M. Spatial Identification and Optimization of Upland Wetlands in Agricultural Watersheds. Ecol. Eng. 2013, 52, 130-142. [CrossRef]

40. Feagin, R.A.; Mukherjee, N.; Shanker, K.; Baird, A.H.; Cinner, J.; Kerr, A.M.; Koedam, N. Shelter from the Storm? Use and Misuse of Coastal Vegetation Bioshields for Managing Natural Disasters. Conserv. Lett. 2010, 3, 1-11. [CrossRef]

41. Van Vuren, S.; Paarlberg, A.; Havinga, H. The Aftermath of 'Room for the River' and Restoration Works: Coping with Excessive Maintenance Dredging. J. Hydro-Environ. Res. 2014, 9, 172-186. [CrossRef]

42. Alcamo, J. Millennium Ecosystem Assessment-Ecosystems and Human Well-Being; Island Press: Washington, DC, USA, 2003.

43. Hanna, D.E.L.; Bennett, E.M.; Tomscha, S.A.; Dallaire, C.O. A Review of Riverine Ecosystem Service Quantification: Research Gaps and Recommendations. J. Appl. Ecol. 2018, 55, 1299-1311. [CrossRef]

44. Nesshöver, C.; Assmuth, T.; Irvine, K.N.; Rusch, G.M.; Waylen, K.A.; Delbaere, B.; Haase, D. The Science, Policy and Practice of Nature-Based Solutions: An Interdisciplinary Perspective. Sci. Total Environ. 2016. [CrossRef]

45. Westermann, F.; Rischer, J.; Ehlscheid, T.; Wanner, S.; Prawitt, O.; Loch, P.; Wendling, K. Gewässerzustandsbericht 2010; Landesamt für Umwelt, Wasserwirtschaft und Gewerbeaufsicht Rheinland-Pfalz: Mainz, Germany, 2011.

46. Grabs, W. Benchmarking Flood Risk Reduction in the Elbe River. J. Flood Risk Manag. 2016, 9, 335-342. [CrossRef]

47. Moss, T.; Monstadt, J. Restoring Floodplains in Europe; IWA Publishing: London, UK, 2008.

48. Albert, C.; Schröter, B.; Haase, D.; Brillinger, M.; Henze, J.; Herrmann, S.; Gottwald, S.; Guerrero, P.; Nicolas, C.; Matzdorf, B. Addressing Societal Challenges through Nature-Based Solutions: How Can Landscape Planning and Governance Research Contribute? Landsc. Urban Plan. 2019, 182, 12-21. [CrossRef] 